\title{
Standards of Nursing Care for Patients Undergoing External Fixation in Trauma Unit At Assiut University Hospital
}

\author{
Soad A. Elhakeem, Zienab A. Ellateef, Osama A. Farouk \& Hala M. Ghanem. \\ Nursing supervisor in Trauma Unit, Assiut University Hospital \\ Professor of Medical- Surgical Nursing ,Faculty of Nursing-Assiut University \\ Professor of Orthopaedic surgery ,Faculty of Medicine- Assiut University \\ Assistant prof . of Medical - Surgical Nursing ,Faculty of Nursing-Assiut University ,Egypt
}

\begin{abstract}
External fixation is a surgical treatment used to set bone fractures in which a cast would not allow proper alignment of the fracture. The aim of study was to explore and develop the established standards of nursing care for patients undergoing external fixation. Subjects and Method : descriptive exploratory was utilized, the study was carried out at trauma unit at assiut university hospital . The study sample divided into all health care provider; 60 nurses, and 10 physicians for the opionnaire sheet. Tools utilized for data collection were health team opionnaire sheet, nurses knowledge standards level test sheet and nurses performance observation standards check list sheet. Results founded that more than two thirds of nurses had good level of knowledge as regarding external fixation patient. The majority of nurses and physicians had agreed as regarding to oppionnaire sheet Nurses founded that about more than half of nurses done steps performance about standards of care of patients undergoing external fixation. conclusion formulation of standards is the first step toward evaluation nursing care delivery. Recommendation : in service training program for nurses is important in trauma unit application of the nursing care study for patients undergoing external fixation.
\end{abstract}

\section{Key Words: Standards Nursing Care, Knowledge, Opionnaie \& Practice.}

\section{Introduction}

The external fixation was introduced in the 1930 and 1940 to provide immobilization of fractures while maintaining the potential for adjusting fractures position. There have been major increases in the frequency of the use of external fixation over the last ten years for several reasons we will discuss after. The first attempt at external fixation a procedure which was reintroduced repeatedly after that by Parkhill, Lambaste (1907), (Conn and others) and later with considerable modifications by Roger Anderson, stander and Haynes. (Edgar, 2004) and (Resnick, and Niwayama, 2004) and (Bentley, and Creer, 2007) The external fixation is a surgical intervention used to set reduction of bone fractures, while cast would not allow proper management of these fractures. In this kind of reduction, holes are drilled into uninjured area of bones around the fracture and special bolts or wires are screwed into the holes outside the body. A rod or a curved piece of metal with special ball and socket joints joins the bolts to make a rigid support. (Marthy, and Glyn, 2004) and (Ritter, 2007) In the united states annually, It has been estimated that between 3.5 and 6 million fractures occur, it can estimated that more than $3 \%$ i.e., 150.000 of these are open fracture. (Praemer, and Charles, 2006) The incidence of external fixation in trauma unit at Assiut University Hospital approximately 340 cases from orthopaedic fractures Form Assiut report during the period between $(2011 / 2012)$.

The external fixation has many indications for fractures associated with severe soft tissue damage, fractured associated with nerve or vessel damage, severely comminuted and unstable fractures, ununited fractures, fractures of the pelvis, infected fractures for which internal fixation might not be suitable and severe multiple injuries.. (Solomon, et al., 2006) and (June et al., 2003)

The external fixation has a lot of advantages such as immediate fracture stabilization, rigid fixation with compression to ensure primary bone healing, facilitates nursing care ability to observe soft tissue injury access to open wound, ability to maintain motion of adjacent joint, decreased blood loss when used for pelvic fracture with compression of bleeding sites, decreased risk of sepsis, facilitation of vascular and soft tissue reconstruction, Improved pulmonary function with improved mobility, fewer complication of immobility with early mobilization, cheap and easily available and reasonable comfortable (Duck Worth, 2004) and (Butler, et al., 2008)

Standards of care (SOC's) are authoritative statements that detail plans of care for individuals with a specific health problem. A standard of care covers a broader range of concerns for the individual than does a protocol. 
The purpose of a standard of care is to establish the best practice and eliminate as much variation as possible. (Janice, et al., 2009)

There are traditional (structural, process and outcome) used for evaluation in health care. Using all three types of standards avoids the limitations that occur if attention is focused on only one type. (Lauristen, and Oden, 2006)

Standards provide a method to assure that patients are receiving high-quality care, that the nurse knows the essentials to provide nursing care. And measures are in place to determine whether the care meets these standards. SOC's reflect both the caring and professional expectations of nursing. Meeting the standard of care involves being technically competent and keeping up to date with nursing SOC's. By virtue of these standards, society holds nurses and those under their supervision accountable for their actions.

(Lauristen, and Oden, 2006)

The standards of care list designated professional nursing responsibilities such as assessment, diagnosis, outcome identification, planning, implementation and evaluation. These responsibilities are inherent in the nursing process. Standards of professional performance include quality of care, performance appraisal, education collegiality, ethics, collaboration, research and use of resources. (Lauritsen and Oden, 2006) (Articles, 2002).

\section{Significance of the study}

Patients with external fixation are need for special nursing care to minimize the risk and /or complications. This study will be the first study in this geographical location which will help such group of patients to maintain and minimize proper nursing care.

According to hospital records at Assiut university Hospital through $(2011,2012)$ the incidence of external fixation patient about 340 cases. So this study was the first nursing study carried out in this geographical location which will help such group of patients to maintain and minimize proper nursing care. The external fixation complications, further more, results of this study could be helpful for health professionals' specialty nurses in planning and implementing standards of nursing care for such group of patients in the future.

\section{Aim of the study}

The aim of this study is to explore and develop the established Standards of nursing care for patients undergoing external fixation.

\section{Subjects and method Research design}

The research design in this study was descriptive exploratory research design was utilized in the study

\section{Technical design}

Setting

This study was conducted in the trauma unit at Assiut University Hospital.

\section{Subjects}

Sample of the study was consist of all health care provider including 60 nurses (10 Baccalaureate degree - 50 Diploma), and 10 physicians for the oppionnaire sheet only who working in trauma unit.

Tools:

Three tools were used in this study and developed by the researcher to collect the necessary data for this study.

\section{Tool I: Health team opionnaire sheet}

A structure opinionnaire was developed by the researcher based on current national and international literature in order to elicit opinions of three groups as regard to the basic nursing competencies for nursing care of external fixation patients.

This tool covered 7 major broad competencies which were subdivided into sub competencies:

1. Ensure that the trauma unit are ready to receive the patient.

2. Ensure that the trauma unit environment is safe to receive patient.

3. Ensures that all infection control measures are properly followed in procedure .

4. Ensures that all pre operative criteria are met for each patient before undergoing external fixation

5. Ensures that safety for each patient during transportation from operating room to the unit

6. Ensures that the post operative criteria are met for each patient monitoring and recording

7. Ensures that all staff (health team are follow ethics and patients right in trauma unit

\section{The scoring system}

The total score of health team opionnaire sheet was 250 items, each item in the sheet was scored as follow: two degree for each step. Agree it means one degree for each step. Disagree it means zero degree for each step.

The scoring system of the nurses' opinionnaire was as follow:

Competencies of care score

Agree

Disagree

1

Tool II: Nurses knowledge standards level test sheet:

This tool was designed and utilized by researcher based on literature review include the following knowledge about basic of nursing care standards for 
patients undergoing external fixation related to the theoretical frame of the actual procedural performance of unit in a patients undergoing external fixation by nurses.

A structured written questionnaire addressed the basic nurses' knowledge for two groups. It include the following parts

\section{Part 1: Socio-demographic data}

This part comprised nurse's age, level of education, sex, and years of experience, marital status, and qualifications.

Part 2: Assessment of nurses' knowledge for patients undergoing external fixation:

This part included definition of external fixation, condition of dressing at the wound of the external fixation, patient directly after operation, factors that lead to delayed wound healing, signs of septic wound, complication of external fixation, signs of vascular problem, uses of external fixation, causes of being the external fixation the common of using.

\section{Scoring system:}

The total number of questions was (36). The total scores were (100). Those who obtained less than $50 \%$ were considered having poor level. While those who obtained 50-70\% were considered having fair level and those who obtained more than $70 \%$ were considered having good level.

\section{Tool III: Nurses performance observation standards check list sheet}

This tool was designed and utilized by researcher based on performances review of related nursing and medical literature in order to identify the level of performance actually carried out by nursing staff in trauma unit at Assiut University Hospital in the form of procedure steps to assess standards practice of nurses providing care for patients undergoing external fixation.

Which contain; hand washing, prepare patient for operation, surgical skin preparation, measuring vital signs, dressing, removing sterile supplies from container, pin site care, giving medication, invasive procedure, and indwelling catheter.

\section{Scoring system}

The total score of observation checklist sheet was 158 items, each item in checklist was scored as follow: two degree for each step that done correct (correctly, in time and with the required frequency) and one degree for each step done incorrect (incorrectly, not in time and without the required frequency) and zero for step that not done. Not inapplicable means that the nurses were not able to apply the principles of the standard due to shortage in supplies and equipment, not due to shortage or negligence from the nurses.

\section{Methods}

A review of current and past, local and international related literature in the various aspects of the problems using books, articles, periodicals, and magazines was done. The proposed study setting was assessed for the numbers of nurses and patients in trauma unit at Assiut University Hospital..

Content validity was established by panel of 5 expertises who reviewed the instruments for clarity, relevance, comprehensiveness, understanding, minor modifications were required. The content validity of this tool was checked by expert professors in fields of medicine and nursing and correction was carried out accordingly.

A pilot study carried out in september 2010 to test the feasibility and practability of the study tools of (6) nurses. It has also provided an estimate of the time needed to fill out the tools, no change was done in the assessment sheet, so the nurses $(10 \%)$ selected for the pilot study were included in the main study. the purpose of the pilot study was:

- To ascertain the relevance of the tools applicability.

- To detect any problem peculiar to the statements clarity that might interfere with the process of date collection

- To estimate the time needed to complete the interview schedule.

An official letter was issued from the Dean of the Faculty of Nursing to the Head of Trauma Unit soliciting the necessary approval to conduct the present research. After explain the aim of the study and the program to them to obtain their cooperation.

Data were collected from Trauma unit at Assiut University Hospital during the period from september (2010) to september (2011). The purpose of the study was explained to the nurses prior to answering the questions. The study was carried out at morning, and after noon shifts. Each nurse was informed with the purpose of the study. The investigator emphasized that the participation is voluntary. Verbal consent was obtained from nurse prior to her contribution in the present study Ethical consideration, the researcher will explain to eligible physicians and all nursing categories of their right to withdraw from the study at any point, and that their participation status would not affect the care they receive. The names will be coded for data entry so that there name could not be identified.

Questionnaire was conducted by the researcher using (tool I) to elicit opinions of the nurses regarding the required competencies.

The basic competencies were formulated in a form of basic standard and criteria for measuring standards of nursing care for patient under going external fixation in the following steps.

Identifying the scope of knowledge and skills required from nurses for interventions of patients undergoing external fixation. (tool I)

Determine the framework of the standards "the process standard and structure standard" were used since it 
describe what the nurse does, assessment techniques and procedures, methods of delivery of care, methods of intervention, preparing trauma unit with necessary equipment and methods of recording.

Determine the level of the standards. In this study, standards of nursing care for patient under going external fixation. the basic level was used, that is to say minimal acceptable level of practice needed by trauma unit nurses. Develop tools to determine the level of achievement of the standards, evaluation, in this study, standards of nurses performance checklists and assessment questionnaire sheet were developed (tool III, tool II) Tool III, II were used to determine the nurses performance and knowledge.

\section{Results}

The results of this study will be presented in four parts as follows.

Part I: Socio demographic data of the nurses:
This part was concerned with the demographic characteristics of the nurses it Include the age, sex, qualification, year of experience and training course:

Part II: Health team opionnaire as regarding the basic nursing competencies required for patients under going external fixations:

This part was developed in order to elicit opinions of (nurses 60) and physician (10) as regards, the basic nursing competencies for patients undergoing external fixation:

Part III: Nurses knowledge as regarding standards of nursing care for patients undergoing external fixation: This part was concerned with assessment of the nurses' knowledge as regarding the standards of nursing care for patients under going external fixation:

Part IV: Nurses performance as regarding the standards of nursing care for patients under going external fixation:

Table (1): Socio-demographic characteristics of nurse (N/s).

\begin{tabular}{|c|c|c|}
\hline Socio-demographic characteristics & No. $(n=60)$ & $\%$ \\
\hline \multicolumn{3}{|l|}{ Age: } \\
\hline$<20$ yrs. & 14 & 23.3 \\
\hline $20-<30$ yrs. M \pm SD $29.3 \pm \mathbf{1 1 . 1}$ & 33 & 55.0 \\
\hline$\geq 30$ yrs. & 13 & 21.7 \\
\hline \multicolumn{3}{|l|}{ Level of education:7 } \\
\hline Diploma & 43 & 71.7 \\
\hline Institute & 7 & 11.7 \\
\hline Baccalaureate & 10 & 16.7 \\
\hline \multicolumn{3}{|l|}{ Years of experience } \\
\hline$<5$ yrs. & 15 & 25.0 \\
\hline $5-<10$ yrs. $\mathrm{M} \pm \mathrm{SD} 9.7 \pm 3.4$ & 30 & 50.0 \\
\hline$\geq 10$ yrs. & 15 & 25.0 \\
\hline \multicolumn{3}{|l|}{ Marital status } \\
\hline Single & 19 & 31.7 \\
\hline Married & 39 & 65.0 \\
\hline Divorced & 2 & 3.3 \\
\hline \multicolumn{3}{|c|}{ Attending training courses about external fixation } \\
\hline Yes & 1 & 1.7 \\
\hline No & 59 & 98.3 \\
\hline
\end{tabular}


Table (2):Percentage distribution to opinions of nurses and physicians as regard prepares the trauma unit with the necessary equipment Nurses (No. 60) \& physicians ( No. 10 ) :

\begin{tabular}{|c|c|c|c|c|c|c|c|c|}
\hline \multirow{3}{*}{ Opinions of nurses } & \multicolumn{4}{|c|}{ Nurses } & \multicolumn{4}{|c|}{ Physicians } \\
\hline & \multicolumn{2}{|c|}{ Agree } & \multicolumn{2}{|c|}{ Disagree } & \multicolumn{2}{|c|}{ Agree } & \multicolumn{2}{|c|}{ Disagree } \\
\hline & No. & $\%$ & No. & $\%$ & No. & $\%$ & No. & $\%$ \\
\hline $\begin{array}{l}\text { Incubation supplies and tubes easily } \\
\text { accessible. }\end{array}$ & 60 & 100.0 & 0 & 0.0 & 10 & 100.0 & 0 & 0.0 \\
\hline Venous access supplies. & 60 & 100.0 & 0 & 0.0 & 10 & 100.0 & 0 & 0.0 \\
\hline $\begin{array}{l}\text { Transport monitors with ECG, pulse } \\
\text { oximetry. }\end{array}$ & 60 & 100.0 & 0 & 0.0 & 10 & 100.0 & 0 & 0.0 \\
\hline Dressing car, suture supplies. & 60 & 100.0 & 0 & 0.0 & 10 & 100.0 & 0 & 0.0 \\
\hline Restraints. & 60 & 100.0 & 0 & 0.0 & 0 & 0.0 & 10 & 100.0 \\
\hline Tracheotomy supplies. & 60 & 100.0 & 0 & 0.0 & 10 & 100.0 & 0 & 0.0 \\
\hline $\begin{array}{l}\text { A portable suction unit with wide bore tubing } \\
\text { and apharyngeal suction tip. }\end{array}$ & 60 & 100.0 & 0 & 0.0 & 10 & 100.0 & 0 & 0.0 \\
\hline Fixed oxygen system. & 60 & 100.0 & 0 & 0.0 & 10 & 100.0 & 0 & 0.0 \\
\hline Oxygen connecter tubing. & 60 & 100.0 & 0 & 0.0 & 10 & 100.0 & 0 & 0.0 \\
\hline Masks and & 60 & 100.0 & 0 & 0.0 & 10 & 100.0 & 0 & 0.0 \\
\hline Nasal canulas. & 60 & 100.0 & 0 & 0.0 & 10 & 100.0 & 0 & 0.0 \\
\hline Cane. & 60 & 100.0 & 0 & 0.0 & 10 & 100.0 & 0 & 0.0 \\
\hline Wheel chair. & 60 & 100.0 & 0 & 0.0 & 10 & 100.0 & 0 & 0.0 \\
\hline ECG set. & 60 & 100.0 & 0 & 0.0 & 10 & 100.0 & 0 & 0.0 \\
\hline Emergency medications. & 60 & 100.0 & 0 & 0.0 & 10 & 100.0 & 0 & 0.0 \\
\hline Resustation equipment. & 60 & 100.0 & 0 & 0.0 & 10 & 100.0 & 0 & 0.0 \\
\hline Laryngo scope. & 60 & 100.0 & 0 & 0.0 & 10 & 100.0 & 0 & 0.0 \\
\hline Suction apparatus. & 60 & 100.0 & 0 & 0.0 & 10 & 100.0 & 0 & 0.0 \\
\hline Air way incubation equipment. & 60 & 100.0 & 0 & 0.0 & 10 & 100.0 & 0 & 0.0 \\
\hline Defibrillator (D.C). & 60 & 100.0 & 0 & 0.0 & 10 & 100.0 & 0 & 0.0 \\
\hline Ambobags. & 60 & 100.0 & 0 & 0.0 & 10 & 100.0 & 0 & 0.0 \\
\hline Different types of intravenous solution. & 60 & 100.0 & 0 & 0.0 & 10 & 100.0 & 0 & 0.0 \\
\hline Sphygmomanometer. & 60 & 100.0 & 0 & 0.0 & 10 & 100.0 & 0 & 0.0 \\
\hline Stethoscope. & 60 & 100.0 & 0 & 0.0 & 10 & 100.0 & 0 & 0.0 \\
\hline Adhesive tape. & 60 & 100.0 & 0 & 0.0 & 10 & 100.0 & 0 & 0.0 \\
\hline Different types of syringes. & 60 & 100.0 & 0 & 0.0 & 10 & 100.0 & 0 & 0.0 \\
\hline Tourniguet. & 60 & 100.0 & 0 & 0.0 & 10 & 100.0 & 0 & 0.0 \\
\hline Intra venous sets. & 60 & 100.0 & 0 & 0.0 & 10 & 100.0 & 0 & 0.0 \\
\hline Oxygen humidifier. & 60 & 100.0 & 0 & 0.0 & 10 & 100.0 & 0 & 0.0 \\
\hline
\end{tabular}

Table (3): Frequency distribution of nurses' knowledge for patient undergoing external fixation $($ No. $60=$ n/s).

\begin{tabular}{|l|c|c|c|c|c|c|}
\hline \multirow{2}{*}{ Nurses' knowledge } & \multicolumn{2}{|c|}{ Incorrect } & \multicolumn{2}{c|}{ Incomplete correct } & \multicolumn{2}{c|}{ Complete correct } \\
\cline { 2 - 7 } & No. & $\%$ & No. & \% & No. & \% \\
\hline Definition of external fixation. & 21 & 35.0 & 0 & 0.0 & 39 & 65.0 \\
\hline $\begin{array}{l}\text { Conditions of dressing at the wound of external } \\
\text { fixation patient directly after operation. }\end{array}$ & 1 & 1.7 & 0 & 0.0 & 59 & 98.3 \\
\hline Factors that lead to delayed wound healing. & 0 & 0.0 & 16 & 26.7 & 44 & 73.3 \\
\hline Signs of septic wound. & 7 & 11.7 & 0 & 0.0 & 53 & 88.3 \\
\hline Complications of the external fixation. & 0 & 0.0 & 60 & 100.0 & 0 & 0.0 \\
\hline
\end{tabular}




\begin{tabular}{|l|c|c|c|c|c|c|}
\hline \multirow{2}{*}{ Nurses' knowledge } & \multicolumn{2}{c|}{ Incorrect } & \multicolumn{2}{c|}{ Incomplete correct } & \multicolumn{2}{c|}{ Complete correct } \\
\cline { 2 - 8 } & No. & $\%$ & No. & \% & No. & $\%$ \\
\hline Signs of vascular problems. & 6 & 10.0 & 0 & 0.0 & 54 & 90.0 \\
\hline Uses of external fixation. & 20 & 33.3 & 0 & 0.0 & 40 & 66.7 \\
\hline Causes of being external fixation the common of using. & 4 & 6.7 & 0 & 0.0 & 56 & 93.3 \\
\hline
\end{tabular}

Table (4) Nurses performance as regarding standards of nursing care for patient undergoing external fixation.

\begin{tabular}{|l|c|c|c|c|c|c|c|c|}
\hline \multirow{2}{*}{ Hand washing } & \multicolumn{4}{c|}{ Done } & \multicolumn{5}{c|}{ Not done } \\
\cline { 2 - 10 } & \multicolumn{2}{|c|}{ Correct } & \multicolumn{2}{|c|}{ Incorrect } & \multicolumn{3}{c|}{ Applicable } & \multicolumn{2}{c|}{ Not applicable } \\
\cline { 2 - 10 } & No. & $\%$ & No. & $\%$ & No. & $\%$ & No. & $\%$ \\
\hline Remove all rings. & 0 & 0.0 & 0 & 0.0 & 60 & 100.0 & 0 & 0.0 \\
\hline Turn on the water and adjust temperature to warm. & 46 & 76.7 & 0 & 0.0 & 14 & 23.3 & 0 & 0.0 \\
\hline Wet hands and lower arms under running water. & 10 & 16.7 & 13 & 21.7 & 6 & 10.0 & 31 & 51.7 \\
\hline $\begin{array}{l}\text { Apply soap and rub palms, wrists, and back of hands } \\
\text { firmly with circular movement 15 to 30 seconds. }\end{array}$ & 4 & 6.7 & 44 & 73.3 & 1 & 1.7 & 11 & 18.3 \\
\hline Clean under finger nails. & 2 & 2.3 & 31 & 51.7 & 0 & 0.0 & 27 & 45.0 \\
\hline $\begin{array}{l}\text { Rinse hands and wrists thoroughly with hands held } \\
\text { lower than fore arms. }\end{array}$ & 0 & 0.0 & 8 & 13.3 & 3 & 5.0 & 49 & 81.7 \\
\hline Dry hand and arms. & 2 & 2.3 & 0 & 0.0 & 58 & 96.7 & 0 & 0.0 \\
\hline
\end{tabular}

Table (1): It was found that the majority of nurses $55 \%$ their age ranged from $20<30$ years $\mathrm{M} \pm$ SD 29.3 $\pm 11.1 .71 .7 \%$ of them had diploma. $50 \%$ of them had ranged from 5-10 years of experience $\mathrm{M} \pm \mathrm{SD} 9.7$ \pm 3.4 . $65 \%$ were married. As regard to previously of attended training programs, it was found that $98.3 \%$ were not attending program about external fixation system.

Part II: Health team of opinionnaire as regarding the basic competencies required for the standards of nursing care for patient undergoing external fixation:

I - Ensures that trauma unit are ready to receive the external fixation patient:

Table (2): Nurses : It was found that the all of nurses (100\%) agreed as regarding prepare the trauma unit with necessary equipment.

Physicians : It was found that the all of physicians agreed as regarding prepare the trauma unit with necessary equipment.

Table (3): It was found that more than one third of nurses $(35 \%)$ answered incorrect as regarding definition of external fixation. (98.3\%) answered complete correct as regarding condition of dressing at the wound of external fixation patient directly after operation. And all of nurses answered incomplete correct as regarding complication of the external fixation.

Table (4): It was found that more than half of nurses not done steps of hand washing.

\section{Discussion}

Based on the results of the present study, the majority of the nurses their ages ranged from 20-<30 years, married, female, and have diploma of nursing. The majority of them have no in-service training course related to external fixation. The majority of them their experiences range from 5 to 10 years.

This result is the same line with Amr, (2012) the current study finding conducted a study medical unit of Assiut University Hospital "effect of designed nursing protocol on nurse's knowledge and practice regarding diabetic patients" the majority of the nurses were married, female, their age ranged from 20-30 years, have a diploma qualification, years of experiences in medical units ranged from 20-30 and have in service training courses related to infection control precautions.

This result contradicted with Xyrichis, and lowton., (2007) who stated that Multi professional education within tissue viability is vital if patients are to receive optimum care and this education should commence at undergraduate level. However, after qualifying, time pressures within healthcare areas can prove to be a barrier for staff wishing to access courses. Staff often rely on advice from peers who may themselves not have accessed the most up-to-date information which can prevent development of evidence based interventions.

Based on the present study, the majority of nurses answered in complete correct as regarding immediate methods of decrease the infection for nursing care for patient undergoing external fixation. The all of nurses answered complete correct as regarding are you think dressing and care of the pin site has important in treatment of patient with external fixation, and we 
should maintain hand washing and use aseptic equipment in dressing of the wound.

This result disagree with Dianne McMahon, (2011) stated that the nurse is responsible and accountable for the quality of nursing care given to patients. The single most important protective strategy for the nurse is to be a knowledgeable and safe practitioner of nursing and to meet the standards of care with all patients. Nurses are empowered by the SOC and the trust of the physician and the patient to ensure quality care.

As regard to ensure that the trauma unit environment are ready to receive the external fixation patient. The majority of nurses and physician had agreed about all components of this competency. This competency include prepare the trauma unit with the necessary equipment, prepare care/table with the necessary equipment, prepare patient room, trauma unit, department, emergency operating, and recovery and rehabilitation.

The present study revealed that majority of nurses and physicians had agreed about ensuring that the trauma unit environment is safe to receive external fixation patient. This competency include hospital acquired infection, Prevention patients falls, reporting accidents and errors, and maintaining safe environment, maintaining safe environment in administrator medicating, maintaining comfort.

Furthermore, the result of this study revealed that more than two third of nurses had good level of knowledge as regarding external fixation. Minority nurses had poor level of knowledge as regarding external fixation. This result agrees with Kabbash, et al., (2009) who found that high level of knowledge regarding blood borne infection. In a more recent study exploring nurses knowledge of universal Precautions. (Buchman, et al., 2004) reported that knowledge was good and agreed with Ahmed, (2003) who found that the level of knowledge among nurses was fair regarding universal infection control precautions.

Furthermore, the result of this study revealed that more than two third of nurses had good level of knowledge as regarding external fixation. Minority of nurses had poor level of knowledge as regarding lower external fixation. This result agrees with Kabbash, et al., (2007) who found that high level of knowledge regarding blood borne infection, especially HIV\& AIDs. In a more recent study exploring nurse's knowledge of universal precautions. (bulteer et al., 2008)

Furthermore, this is in accordance with Mohamed, (2000) who mentioned that nurses are lacking in theoretical and practical skills needed for patient assessment. Other factors that affect nurse's practice are the shortage of the nurse's number, and overlapping of nursing activities especially in morning shifts due to absence and ignorance of clear job description. This interpretations in the same line with Ead, (2007) who stated that lack of nurse' practice related to absence of definite job description and policy.

This result may be attributed to insufficient courses related to external fixation included in their undergraduate curriculum of nursing education. Most nurses stated that their knowledge gained while working with patients. Also there is no Arabic source for updating and continuing their education.

Based on the present study that more than half of nurses not done steps of hand washing. This study is disagreed with Doug Elliott, (2012) who stated that hand washing is important to avoid spread of infections.

Huston, \& Marry, (2010) stated that education and training are two components of staff development that occur after an employees' indoctrination (which refers to planned, guided adjustment of employee to the organization and work environment). The staffs' knowledge level and capabilities are a major factor in determing the number of staff required to carry out unit goals. The better trained and more competent the staff, the fewer staff required, which in turn saves the organization many and rise productively.

\section{Conclusions}

Formulation of standards is the first step toward evaluating nursing care delivery. Moreover, standards of care have many advantages. They conserve valuable nursing time, ensure that patient's specific nursing diagnosis receive the highest standard of care, promote continuity of care, provide basis for nursing care evaluation while ensuring accountability in practice by achieving competence in performance.

The first step of the quality cycle is to have structure standards for the hospital. The next step of the quality cycle is to describe nursing, or what nurses do in measurable terms. Then, it is necessary to identify standards and criteria in order to establish the quality of nursing services

Based on finding of this study, it can be concluded that.

The aim of this study is to explore and develop the standards of nursing care for patients undergoing external fixation. There been major inceeases in the frequency of use of external fixation in the last yeare Advances in soft tissue plastic reconed for stabilization of the skeleton in a manner which can only be supplied by external fixation . similar advances in bone reconstructive surgery for infected non - union and for traumatic bone loss require prolonged stabilization of the skeleton , and external 
skeletal fixation have been found to be most effective for this purpose . ( Bently and Rober ,2002)

\section{Recommendations}

Based on the finding of the present study the following recommendations are suggested:

A. For the nurses

B. Application of the nursing care standards for standards of nursing care for patient under going external fixation.

1. The nurse should be aware that the application of nursing care standards:

- Facilitate achievement of established nursing goals.

- Improves nurse's knowledge, attitude, skills and their ability to help those patients

- Measures nursing competency and evaluate the quality of nursing services.

- Helps in early detection and prevention of complication.

C. For the administration

1. Establish on effective training program on nursing intervention of post stroke patients rehabilitation, should be well organized with both Assuit hospital unit and general hospital and equipped with necessary education and facilities.

2. Plan periodical sessions of regular conferences, workshops for nurses to upgrade their level of experience.

3. Clear written job description for all nurses in caring for external fixation patient.

C. For the government

1. Standard nursing care for external fixation patients should be included in the curriculum of nursing school and institutions as a minor specialty.

2. Nursing standards must be designed and communicated to all nursing staff in each hospital to improve of care rendered.

\section{References}

1. Ahmed, G., (2011). Effect of designed nursing protocol on nurses's knowledge and practice regarding haemodialysis patients.

2. Bently, G., \& Creer, A., (2007). Operative Surgery (Rob and Smith's). Procedure to introduce the external fixation. 4th ed, pp. 145.

3. Bulter, A., Salmond, S., \& Pellino, T., (2008). Orthopaedic Nursing. Advantages of external fixation. 2nd ed. pp. 318.

4. Canale, T., \& Daughert, K., (2003). Operative Orthopedics (campbelle's). Physician and external fixation. 7th ed. pp. 2018.
5. Dianne McMahon (2011). HG.Org World Wide Legal Directories. Standards of care. HGExperts.com

6. Duck Worth, T., (2004). Ortho paedics and Fractures (lecture Notes). Advantages of external fixation. pp. 45.

7. Ead, A., (2007). Developing Standards of Intraoperative Nursing Interventions for General Surgery.

8. Edgar, M., (2004). Source Book of Orthopaedic. The first attempt external fixation. 2nd ed. pp. 311.

9. Janice, R., Celia, L., Elizabeth, N., Helen, K., \& Martin, A., (2009). Nursing Care and structural standards. 5 th ed.chapter 7.pp (359264)

10. June, M., Gertrude, K., Jane, E., \& Susan, M., (2003). Mosby's Clinical (Nursing). Contraindication of external fixation. 4th ed. pp.436.

11. Lauristen, B., \& Oden, E., (2006). Foundation of Nursing. Standards of practice. 5th ed. pp. 2527.

12. Marthy, J., \& Glyn, A., (2004). Hip Fracture Management. Definition of external fixation. pp. 199.

13. Praemer, A., \& Charles, E., (2005). Musculoskeletal Condition in the United Statety park Ridy e III Academy of orthopedics Surgeon. Tetanus given as prevention and wound dressing. www.ijooline.com/artivcel.asp?iss= oolg-5413. year $=2008$. volume

14. Resnick, D., \& Niwayama, G., (2004). Diagonsis of Bone and Joint disarders, introduction of external fixation 1930 and 1940. 2nd ed. pp. 532.

15. Ritter, R., (2007). The Oxford Style Manual Oxford University press. Definition of external fixation. http.//wikpidia.org/wrki/External ficatiun, pp115.

16. Solomon, l., War Wick, D., \& Nagagam, S., (2006). System of Orthopedics and Fractures (Apledy's). Complication of external fixation. 8th ed. pp. 556-557.

17. Susan, S., (2004). Perioperative Nursing (Principled and Practice). Position the surgical patient.pp.299.

18. Xyrichis, A., Lowton, K., (2007). What fosters or prevents interprofessional team working in primary and community care? A literature review. 